\title{
APPLICATION OF EARTH OBSERVATION DATA FOR ESTIMATION OF CHANGES IN LAND TRAJECTORIES IN VARANASI DISTRICT, INDIA
}

\author{
Sunita Singh, PRAVEEN KuMAR RAI \\ Department of Geography, Institute of Science, Banaras Hindu University, \\ Varanasi-221005, U.P., India \\ *Corresponding author:email - rai.vns82@gmail.com
}

Received: $8^{\text {th }}$ May 2017, Accepted: $14^{\text {th }}$ July 2017

\begin{abstract}
AbSTRCT
Digital change detection is the process that helps in shaping the changes associated with land use land cover (LULC) properties with reference to geo-registered multi-temporal remote sensing data. In this study different methods of analyzing satellite images are presented, with the aim to identify changes in land cover in a certain period of time (1980-2016). The methods represented in this study are vegetation indices, image differencing and supervised classification. These methods gave different results in terms of land cover area. Urban expansion has brought serious losses of agriculture land, vegetation and water bodies. The present study demonstrates changes in land trajectories of Varanasi district, India using Landsat MSS (1980), TM (1990 and 2010), ETM+ (2000) and Landsat-8 OLI data (2016). The LULC classes in the study area are divided into eight categories using supervised classification method. Normalized Difference Vegetation Index (NDVI) and Soil Adjusted Vegetation Index (SAVI) are also calculated to estimate the changes in LULC classes during these time periods. Major changes are seen from 2000 to 2016 for the built-up, agriculture land, water bodies and wasteland.
\end{abstract}

Keywords: Land use Land cover, Change detection, Landsat, remote sensing, supervised classification, NDVI, SAVI.

\section{INTRODUCTION}

Land use land cover changes (LULC) need monitoring of Earth resources, and advantage greatly from remote sensing data that have the ability to gather enormous amounts of data economically and frequently for huge areas compared to field approaches (Van Lynden \& Mantel, 2001). These tools are vital in order to examine the consequences of climate change, whereby land use plays a critical role by inducing the surface-energy budgets as well as the carbon-cycle effects (Pielke et al., 2002). Its studies have become very interesting over the past decades through using Earth observation data because of the availability of sensors operating at various imaging scales and scope of using various techniques as well as considered the good ways for effective monitoring and accurate estimation of changes in natural and man-made areas (Rai et. al., 2011). Knowledge of land use and land cover is important for many planning and management activities and is considered an essential 
Singh S., Rai P.K..: Application of Earth observation data for estimation of changes in land trajectories in Varanasi District, India

element for modeling and understanding the earth as system (Lillesand et al., 2008; Mishra \& Rai, 2014; Prajapati, 2016). LULC changes are affected by human interference and natural phenomena such as agriculture, population growth, consumption, patterns, urbanization, economic development etc. As significance, timely and precise information about LULC change detection of the area of interest is tremendouslysignificant for understanding relationships and interactions between human and natural resources for better decision making (Vishwakarma et.al., 2016).

Remote Sensing (RS) and related technique a valuable tool for understanding and managing Earth natural resources and detecting the changesfrom one time period to another's (Matinfar et al., 2007; Rai et al., 2015; Mishra \& Rai, 2016; Mishra et.al., 2016). Enormous efforts have been made to delineate LULC on a local scale as well as global scale by applying different multi-temporal and multi-source remotely sensed data from both airborne and space borne sensors. Medium resolution satellite imagery such as Landsat satellite data, are the most widely used data types of monitoring and mapping land cover changes (Williams et al., 2006). They have been successfully utilized for monitoring LULC changes especially in the land that has been affected by human activity to various degrees, for example, Junfeng et al. (2011) used Landsat Multi-Spectral System (MSS), Landsat TM and ETM+ remote-sensing data for land cover changes. Fan et al. (2007) used TM and ETM+ images for detecting and predicting land use and land cover in the Core corridor of Pearl River Delta (China). Zaki et al. (2011) applied Landsat images (TM) for detecting land cover changes in Northeast Cairo, Egypt. Not only Landsat data have shown the ability to detect LULC changes but data from other sensors are equally useful in monitoring LULC changes. Chavula et al. (2011) showed the RADAR and Advanced Very High Resolution Radiometer (AVHRR) and Moderate-resolution Imaging Spectro-radiometer (MODIS) sensor data is able to detect LULC in the Lake Malawi Drainage Basin.

The change detection frameworks use multi-temporal datasets to qualitatively analyze the temporal effects of phenomena and quantify the changes (Singh, 1989). The RS data has become a major source for change detection studies because of its high temporal frequency, digital format suitable for computation, synoptic view, and wider selection of spatial and spectral resolutions (Lunetta, 2004).

The general objectives of change detection in RS include identifying the geographical location and type of changes, quantifying the changes, and assessing the accuracy of change detection results (Coppin et al., 2004; Im \& Jensen, 2005).

\section{STUDY AREA}

The research study area i.e. Varanasi district, extending between $25^{\circ} 10^{\prime}$ to $25^{\circ} 37^{\prime} \mathrm{N}$ latitude and $82^{\circ} 39^{\prime}$ to $83^{\circ} 10^{\prime} \mathrm{E}$, which is a part of eastern Uttar Pradesh in India. The district has an area of 1535 sq.km; physiographically it lies in the Middle Ganga Plain. The study area is bounded by river Gomati and Jaunpur district in the north, Mirzapur in south, Sant Ravidas Nagar Bhadohi in the west and Chandauli district in the east. Topographically the study area is covered by the alluvial deposits of Quaternary age. The Ganga is the main river of the District. Geologically the area is constructed by Gangetic alluvium formed by the deposition of the sediments brought by the Ganga River and its tributaries. Location of the study area is shown in the Fig. 1. 
Fig. 1: Location of the study area as viewed on Landsat 8-OLI data
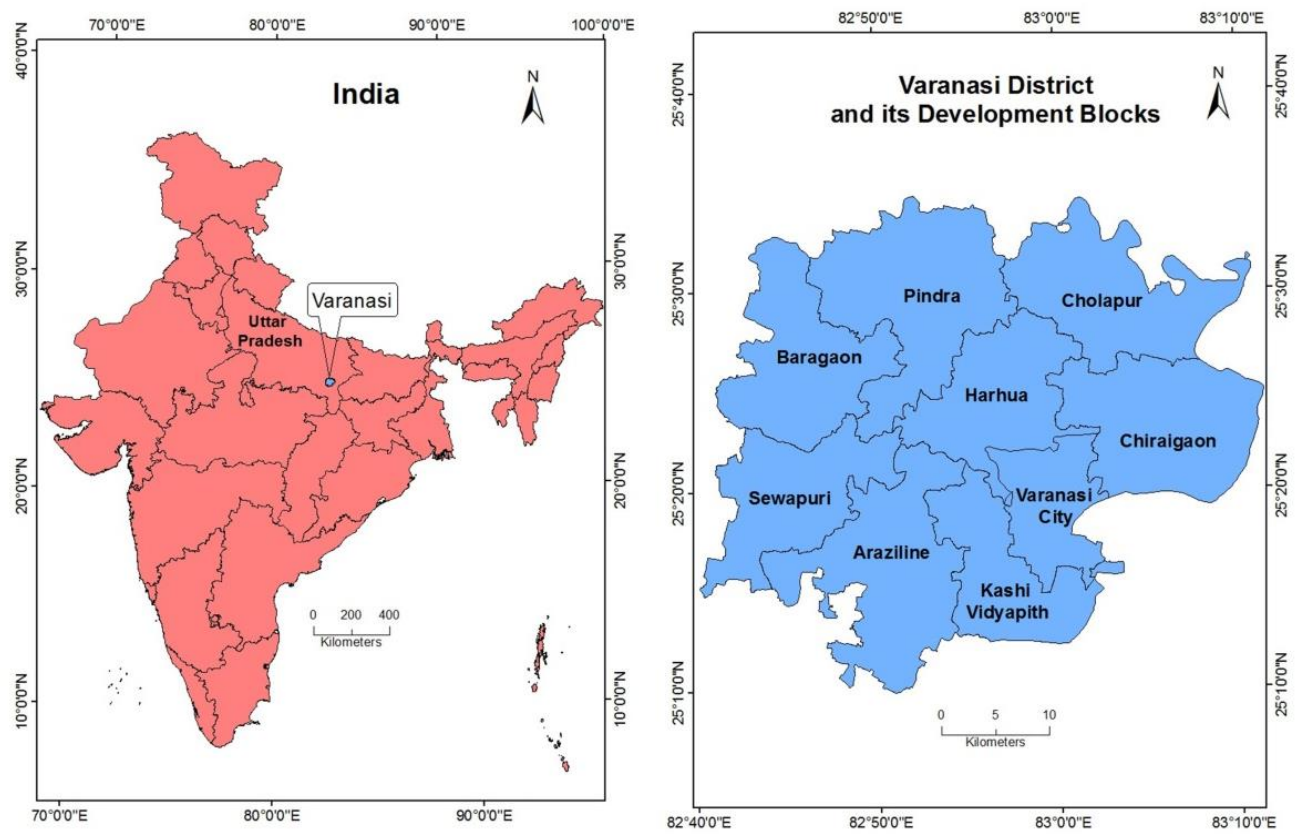

$82^{\circ} 45^{\prime} 0$ "E

$83^{\circ} 0^{\prime} 0 " \mathrm{E}$

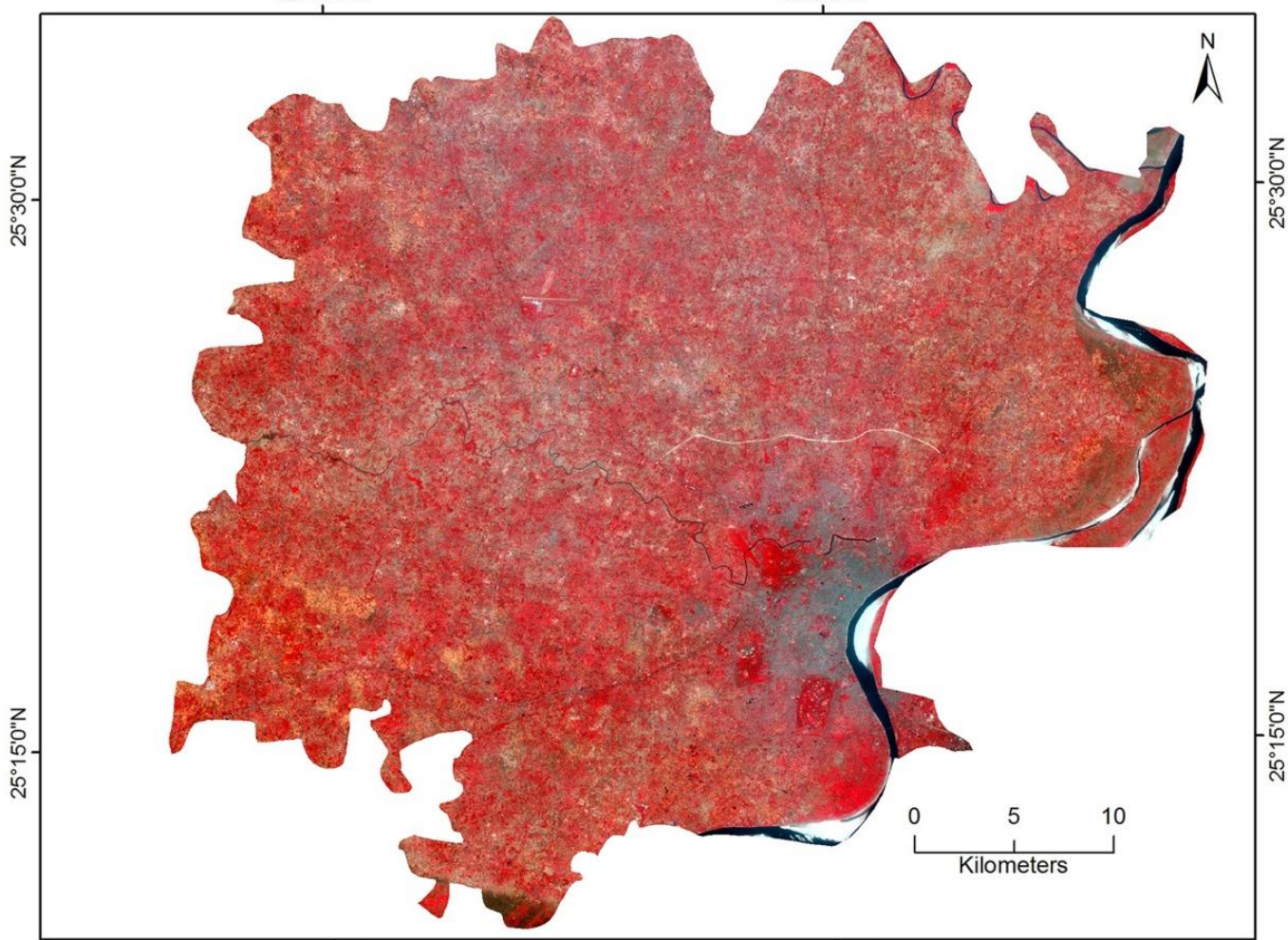

$82^{\circ} 45^{\prime} 0 " \mathrm{E}$

$83^{\circ} 0^{\prime} 0 " \mathrm{E}$ 
Singh S., Rai P.K..: Application of Earth observation data for estimation of changes in land trajectories in Varanasi District, India

\section{DATA USED AND METHODOLOGY}

Survey of India toposheet at the scale of 1:50,000 is used to demarcate the district boundaries. The satellite multi-temporal images of multi-sensor data have been used in the study.

In this study, LUCC were prepared from Landsat data at decadal interval in ERDAS IMAGINE 9.3. Landsat MSS (1990), Landsat-7 ETM+ (2000), Landsat-5 TM (2010) and Landsat-OLI (2016) were downloaded from the U.S. Geological Survey (www.usgs.gov.in). Then datasets were corrected in ENVI-5.3 software. Following acquisition, all bands of MSS, TM, ETM and OLI data were stacked as a single image for each scene. Mosaicing of two consecutive scenes was performed after image stack. Thereafter, using nearest-neighbour method images were resampleand projected in UTM projection system (datum WGS 1984, 44 N zone).

Before the classification, the dataset were masked for the study area. Details of Landsat images used in the study are given in the Table 1 . The detailed step wise processes are incorporated in the paper which is given below:

(i) The classification approach is most suitable to prepare land use/cover maps from remote sensing data, specifically Landsat data (Alrababah \& Alhamad, 2006; Rozenstein \& Karnieli, 2011; Zhu \& Woodcock, 2014). Supervised classification provides unsatisfactory classification results resulting from spectral confusion. Spectral similarity of various objects causes such confusion. For example, barren land and agricultural fallow land; settlement, and open forest each are often erroneously classified into other class. To avoid such problems, post classification processing of the classified maps was employed in the study. The post classification processing included in this study is recoding of classified erroneous classes to appropriate classes based on digitized polygons of LULC classes obtained from Google earth image and satellite images.

(ii) There are two basic ways of change detection: first by direct overlapping of classified vector classes from both images and then visually analyzing the changes and second by direct change detection of one image made of combined images from different times (Jovanović et al., 2007; Jovanović et al., 2011). The classified LULC maps were employed for change detection analysis. Change detection matrix tool in ERDAS IMAGINE 9.3 was used to estimate the transition of each of the classes to another class (from-to) for four LULC maps prepared at decadal interval. Finally, dynamics in LULC classes are assessed. For the estimation of LULC conversion, a confusion matrix was prepared in MS Excel and net conversion (gain or loss) of each land cover from/to other classes was estimated.

(iii) Accuracy assessment is used to evaluate the quality of the information of LULC maps generated from the remotely sensed data. It is more essential in digital image classification to verify classified maps by comparing the classification output with some ground reference data like, ground truth collected from the field, aerial photographs, and reference LULC map obtained from secondary sources. The LULC classification results were evaluated by employing accuracy assessment technique using ERDAS Imagine 9.3 software. The error matrices were plotted as cross-tabulations of information obtained from classified maps versus the GPS data. Hence, overall accuracy, user's and producer's accuracies and the kappa statistic were estimated from the error matrices. In an error matrix or confusion matrix, reference data are tabulated in row, while classified image data are placed in 
column. In such matrix the each elements in the major diagonal $\left(C_{i i}\right)$ represents the number of pixels classified correctly for class $i$. Any element off the major diagonal $\left(C_{i j}\right)$ represents the number of pixels that should be in class $i$ but which are incorrectly classified as class $j$ (Liu \& Mason, 2009). The overall accuracy is estimated by taking the ratio between sum of the major diagonal elements and the total number of pixels $(N)$. The following equation used for determination of user's accuracy, producer's accuracy and kappa coefficient $(\mathrm{k})$ :

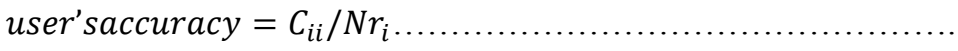

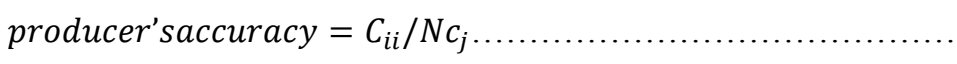

Kappa coefficient $(k)=\frac{N \sum_{i=1}^{m} C_{i i}-\sum_{i=1}^{m} N r_{i} . N c_{j}}{N^{2}-\sum_{i=1}^{m} N r_{i} \cdot N c_{j}} \ldots \ldots \ldots \ldots \ldots \ldots \ldots$

where, $N r_{i}$ is sum of any row $i$ and $N c_{j}$ is sum of any column $j$ in the confusion matrix.

(iv) Change in LULC with the use of the vegetation indices included the classification with the help of vegetation indices between 1990 and 2016 is detected. Vegetation indices are quantitative measurements indicating the dynamism of vegetation. (Campbell, 1987). They show better sensitivity than individual spectral bands for the detection of biomass (Asrar et al., 1984). The interest of these indices lies in their usefulness in the interpretation of remote sensing images; they constitute notably a method for the detection of land use changes (multi temporal data), the evaluation of vegetative cover density, crop discrimination and crop yield prediction. In the area of thematic mapping, the interest of most of these indices lies inthe improvement of classifications (Asrar et al., 1984; Qi et al., 1991; McNairn \& Protz, 1993). In this study NDVI index was used in order to monitor vegetation cover changes during different time periods. Normalized Difference Vegetation Index (NDVI) is the most widely used vegetation index to distinguish healthy vegetation from others orfrom non-vegetated areas (Manandhar et al., 2009). NDVI represents the ratio between the red (Red) and near infrared spectrum (NIR) and was first used by Rouse et al. (1973). Healthy plants absorb most of the visible light and reflect the large amount of the far-red and near-infrared light (Fluor, 2014). It is obtained from the Equation 1. Theoretically, the values of this index will vary within the range of -1 to 1 . The study shows that the values of NDVI index for vegetation are within the range between 0.3 and 0.7 ; the values above 0.6 indicated the presence of dense vegetation in the area. The NDVI has been calculated by the given formula:

$$
\text { NDVI }=\frac{\text { NIR- Red }}{\text { NIR+Red }}
$$

(v) To reduce the impact to the NDVI from the soil variations in lower vegetation cover areas, Huete (1988) proposed the Soil-Adjusted Vegetation Index (SAVI) by introducing a correction factor $L$ (Yang et al., 2008). The SAVI was found to be an important step toward the establishment of simple "global" model that can describe dynamic soil vegetation systems from remotely sensed data (Huete, 1988). In areas where vegetation cover is low and the soil surface is exposed, the reflectance of 
Singh S., Rai P.K..: Application of Earth observation data for estimation of changes in land trajectories in Varanasi District, India

light in the red and near-infrared (NIR) spectra can influence ND vegetation index values (Huete, 1988). This is especially problematic when comparisons are being made across different soil types that may reflect different amounts of light in the red and near infrared wavelengths (Huete et al., 2002). The soil-adjusted vegetation index (SAVI) was developed as a modification of the normalized difference vegetation index (NDVI) to correct for the influence of soil brightness when vegetative cover is low (Huete, 1988; Richardson \& Everitt, 1992; Rondeaux et al., 1996; Senseman et al., 1996; Lyon et al., 1998). The SAVI is structured similar to the NDVI but with the addition of a "soil brightness correction factor" (Huete, 1988).

In areas where vegetative cover is low (i.e., <40 \%) and the soil surface is exposed, the reflectance of light in the red and near-infrared spectra can influence vegetation index values. This is especially problematic when comparisons are being made across different soil types that may reflect different amounts of light in the red and near infrared wavelengths (i.e. soils with different brightness values). The Soil Adjusted Vegetation Index (SAVI) is structured similar to the NDVI but with the addition of a "soil brightness correction factor,"where, NIR is the reflectance value of the near infrared band, RED is reflectance of thered band, and L is the soil brightness correction factor. The value of $\mathrm{L}$ varies by the amount or cover of green vegetation: in very high dense vegetation regions, $\mathrm{L}=0$; and in areas with no green vegetation, $\mathrm{L}=1$. Generally, an $\mathrm{L}=0.5$ works well in most situations and is the default value used. When $\mathrm{L}=0$, then SAVI = NDVI.

$$
S A V I=\frac{N I R-R E D}{(N I R+R E D+L)}^{*}(1+L)
$$

\section{Table 1: Details of Landsat images used in the study}

\begin{tabular}{|c|c|c|c|}
\hline Satellite-sensor & Path/row & Date of acquisition & Cloud Coverage \\
\hline Landsat 3-MSS & $\begin{array}{l}142 / 42 \\
142 / 43\end{array}$ & 10 February, 1980 & $5 \%$ \\
\hline Landsat-5 TM & $\begin{array}{l}142 / 42 \\
142 / 43\end{array}$ & 18 February. 1990 & No \\
\hline Landsat 7-ETM+ & $\begin{array}{l}142 / 42 \\
142 / 43\end{array}$ & 03 February 2000 & No \\
\hline Landsat 5-TM & $\begin{array}{l}142 / 42 \\
142 / 43\end{array}$ & 02 February 2010 & No \\
\hline $\begin{array}{c}\text { Landsat 8-OLI } \\
\text { TIRS }\end{array}$ & $\begin{array}{l}142 / 42 \\
142 / 43\end{array}$ & $\begin{array}{ll}03 \text { February, } \\
2016\end{array}$ & No \\
\hline
\end{tabular}

\section{RESULT AND DISCUSSION}

\section{Assessment of LULC change}

The whole study area has been classified into eight classes. Land use land cover (LULC) maps prepared at decadal interval and there has been a positive and negative variation in each category at each decadal interval. The area falling under each category for different five years $(1980,1990,2000,2010,2016)$ has been given in table 1 . There has been gradual decrease in 
area of water bodies in each decadal year. The fallow land area has increased from $25.92 \%$ in the year 1980 to 1990 and decreased $13.12 \%$ in the year 1990 to 2000, and again decreased $7.80 \%$ in the year 2010 to 2016. The crop land area has decreased in 1980-1990 from $45.55 \%$ to $41.91 \%$ but from 1990 to 2010 it has increased. The area under this category in 2010 was $60.19 \%$ but gradually decreased to $53.07 \%$ in 2016.There is not very remarkable change in the area of sand bars. The area of barren land has reduced from 1980 to recent years from $8.70 \%$ to $1.28 \%$. In 1980, the built up area was $5.17 \%$ while it is $23.82 \%$ of total area in 2016. It means that the built up land has increased in due respect of time. The maximum changes have been seen in the data depicting settlements and roads.

The changes in settlements are found mainly in the area around Varanasi city and its surroundings. The negative changes have been seen in vegetation from 1980 to 2010 which is mostly cleared for making settlements and roads. It has decreased during 1980 to 2010 but it shows gradually increase from 2010 to 2016 due to awareness of the people and government plan. The marsh area has decreased from $7.61 \%$ in year 1980 to $0.07 \%$ in the year 2016. It is noticed that a heavy flood in Varanasi in 1978 which increased marsh land during these time periods. During the study, it is shown that the area under the vegetation or orchards has decreased from $1980(14.26 \%)$ to $2016(9.65 \%)$.

Table 2: Area Distribution of Land Use Land Cover (\%)

\begin{tabular}{|c|c|c|c|c|c|}
\hline LULC classes & $\begin{array}{c}\text { Area (\%) } \\
\mathbf{1 9 8 0}\end{array}$ & $\begin{array}{c}\text { Area (\%) } \\
\mathbf{1 9 9 0}\end{array}$ & $\begin{array}{c}\text { Area (\%) } \\
\mathbf{2 0 0 0}\end{array}$ & $\begin{array}{c}\text { Area } \\
(\mathbf{\%}) \\
\mathbf{2 0 1 0}\end{array}$ & $\begin{array}{c}\text { Area (\%) } \\
\mathbf{2 0 1 6}\end{array}$ \\
\hline Water body & 2.77 & 2.75 & 1.87 & 1.86 & 1.99 \\
\hline Fallow Land & 14.20 & 40.12 & 27.00 & 17.87 & 10.07 \\
\hline Crop Land & 45.55 & 41.91 & 48.19 & 60.19 & 53.07 \\
\hline Sand Bar & 1.21 & 0.95 & 1.38 & 1.30 & 1.28 \\
\hline Barren Land & 8.70 & 0.96 & 0.17 & 0.01 & 0.03 \\
\hline Built Up Area & 5.17 & 6.94 & 12.42 & 14.13 & 23.82 \\
\hline Vegetation or Orchards & 14.76 & 6.13 & 8.90 & 4.63 & 9.65 \\
\hline Marsh Land & 7.61 & 0.69 & 0.04 & 0.01 & 0.07 \\
\hline Total Area & 100 & 100 & 100 & 100 & 100 \\
\hline
\end{tabular}

Table 3: Changes in LULC during 1980-2000, 2000-2016, and 1988-2016

\begin{tabular}{|l|c|c|c|}
\hline \multicolumn{4}{|c|}{ Changes in Area (\%) } \\
\hline Period/LULC class & $1980-2000$ & $2000-2016$ & $1980-2016$ \\
\hline Water body & 0.90 & -0.12 & 0.78 \\
\hline Fallow Land & -12.8 & 16.93 & 4.13 \\
\hline Crop Land & -2.64 & -4.88 & -7.52 \\
\hline Sand Bar & -0.17 & 0.10 & -0.07 \\
\hline Barren Land & 8.53 & 0.14 & 8.67 \\
\hline Built Up Area & -7.25 & -11.4 & -18.65 \\
\hline $\begin{array}{l}\text { Vegetation } \\
\text { or Orchards }\end{array}$ & 5.86 & -0.75 & 5.11 \\
\hline Marsh Land & 7.57 & -0.03 & 7.54 \\
\hline
\end{tabular}

Note: Positive (+) value indicate gain in the area whereas negative (-) value indicate loss in area 
Fig. 2: LULC classes of Varanasi in (a) 1980, (b) 1990, (c) 2000, (d) 2010 and (e) 2016
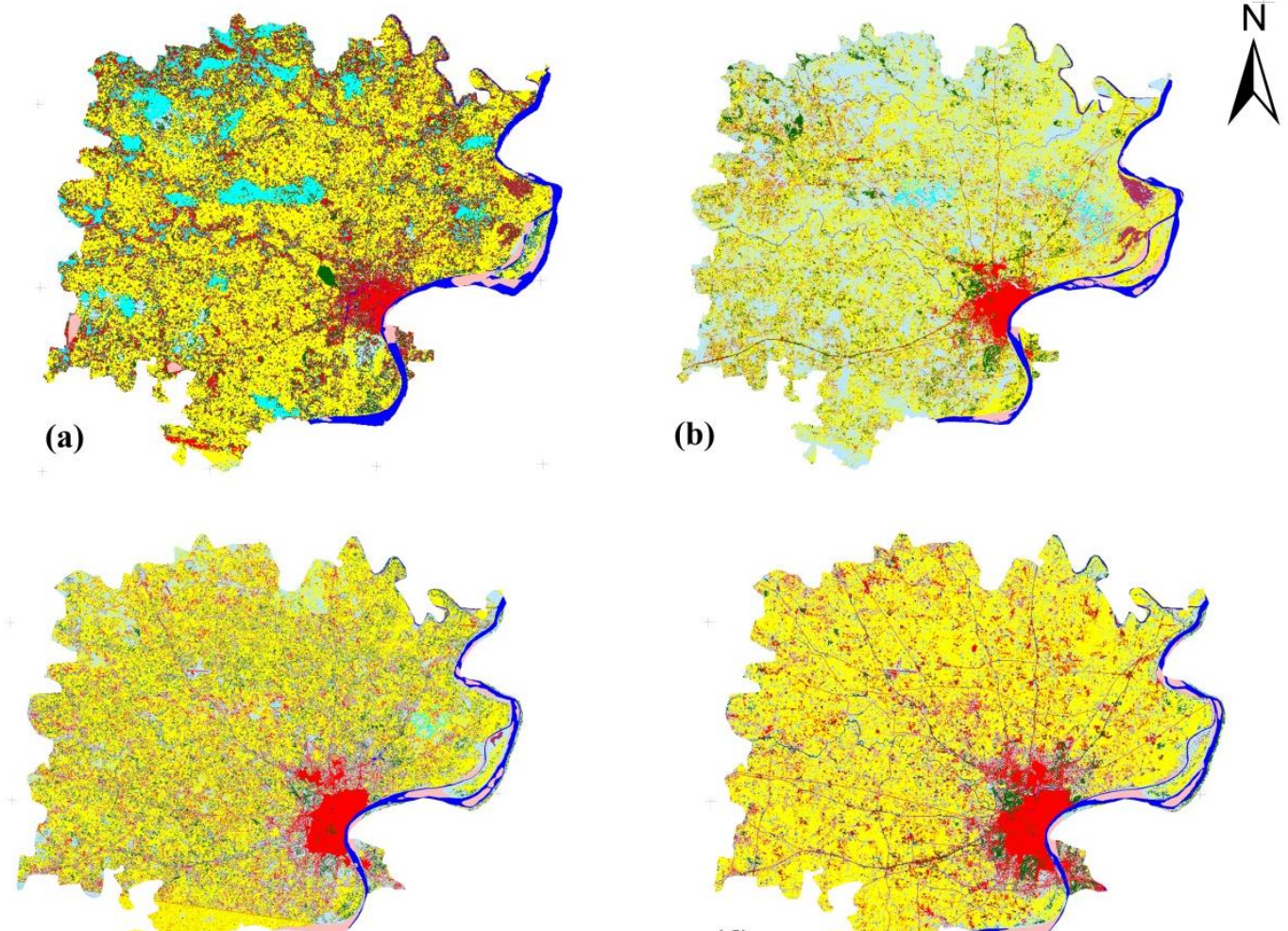

(c)
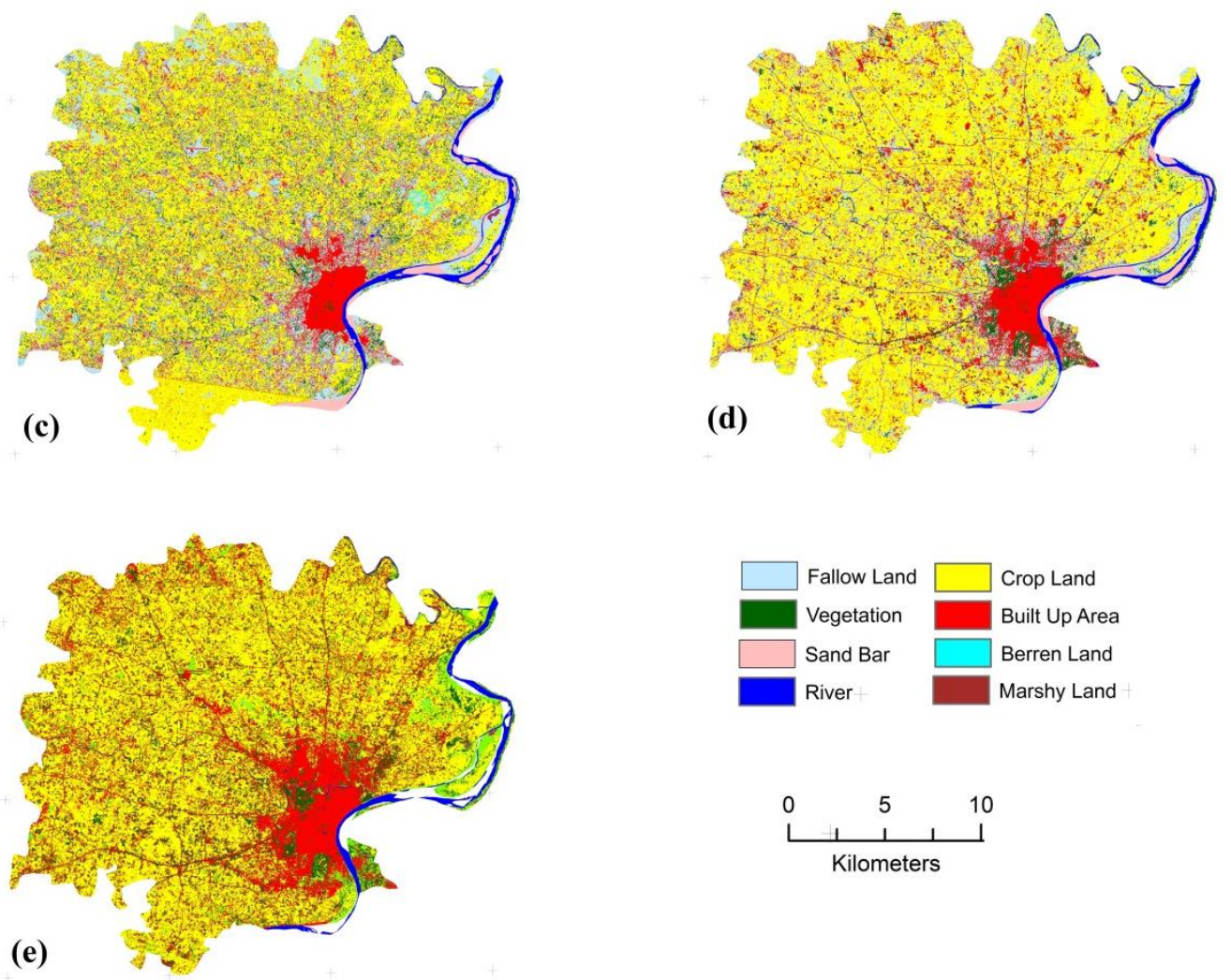

The LULC classes of Varanasi district during different time periods are shown in the Fig. 2 (a-e). The area distribution and changes in LULC classes are given Table 2 and Table 3.

The ground truth data collected with GPS were used as the reference for assessing the accuracy of classification. The accuracy and KAPPA statistic of the classified image checked with the help of accuracy assessment. The overall accuracy of the image is given in the Table 
4. The value of KAPPA in the image is moderate agreement for 1980 and 2016 while it's very strong agreement for the year 2000 .

Table 4: Overall accuracy of classified images of different years

\begin{tabular}{|c|c|}
\hline Year & Overall accuracy \\
\hline 1980 & $78 \%$ \\
\hline 1990 & $84 \%$ \\
\hline 2000 & $89 \%$ \\
\hline 2010 & $80 \%$ \\
\hline 2016 & $90 \%$ \\
\hline
\end{tabular}

\section{Analysis of NDVI and SAVI images for land use estimation}

NDVI takes values between -1 and 1 , with values $>0.5$ are indicating dense vegetation and values $<0$ indicating no vegetation. NDVI has proved to have an extremely wide (and growing) range of applications. It is used to monitor vegetation conditions and therefore provide early warning on droughts and famines. By combining the two channels in a ratio or difference, allows the response to vegetation growth to be distinguished from the background signal. By normalizing the difference in this way, the values can be scaled between values of -1 to +1 . This also reduces the influence of atmospheric absorption which shows typical reflectance values in the red and infrared channels, and the NDVI for typical cover types. Water typically has an NDVI value less than 0 , bare soils between 0 and 0.1 and vegetation over 0.1 .

During the study, the SAVI values are calculated which are ranging from -0.176 to 1.161 . The highest value is 1.161in 1980 and lowest value found in 2016. In order to assess the degree of vulnerability, the Soil Adjusted Vegetation Index (SAVI) was implemented to the 1980,1990, 2000 and 2016 satellite images. The visual differences of the landuse/land cover were clearly depicted and are shown in (Figs. 2) Looking at the picture, there was an overall decrease in SAVI vegetation reflectance values in the wholestudy area. Vegetation cover indicates serious vegetation degradation over time. Therefore, SAVI values were more variable. The first results clearly indicate that there is a proportion distribution of vegetation cover areas using SAVI created images during the period in the study area; hence, the most important factor indicating degradation of vegetation cover is the decline of land productivity.

On the whole, SAVI vegetation values decreased from 1.161 in 1980 to 0.1 in 2016 of the study area (Table 5). 
Singh S., Rai P.K..: Application of Earth observation data for estimation of changes in land trajectories in Varanasi District, India

Fig. 3: NDVI images in (a) 1980, (b) 1990, (c) 2000, (d) 2010 and (e) 2016

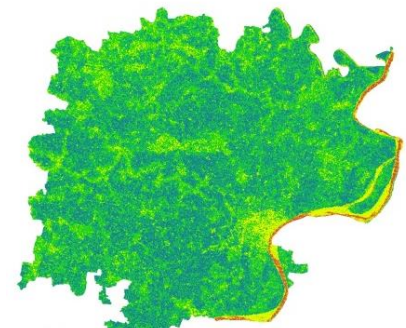

(a)
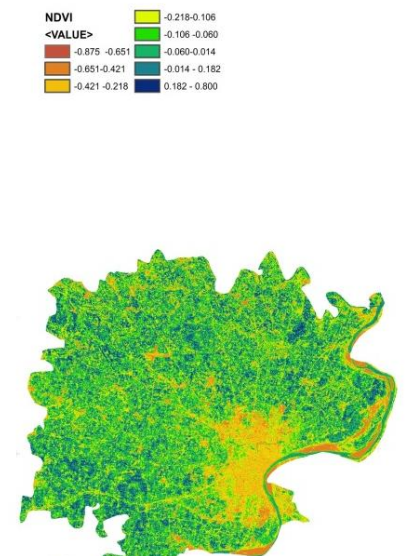

(d)

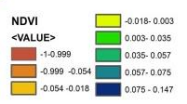

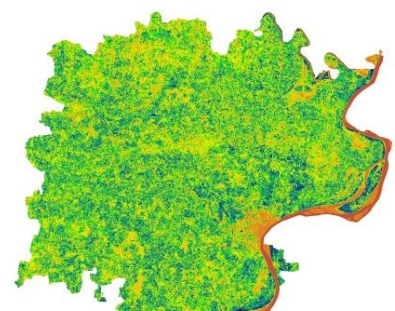

(b)

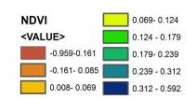

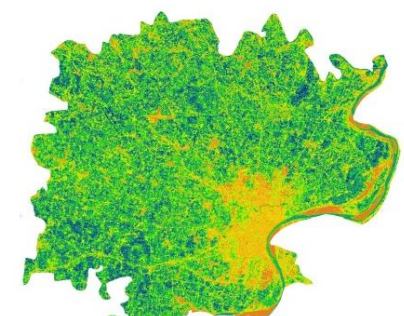

(c)

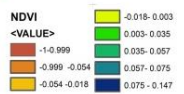

Table 5: Values of SAVI for different years

\begin{tabular}{|l|c|c|c|c|c|}
\hline SAVI value & 1980 & 1990 & 2000 & 2010 & 2016 \\
\hline (Low to High) & -1.241 & -1.424 & -1.486 & -1.486 & -0.176 \\
& to & to & to & to & to \\
& 1.161 & 0.885 & 0.901 & 0.219 & 0.133 \\
\hline
\end{tabular}


Fig. 4: Results of SAVI image in (a) 1980, (b) 1990, (c) 2000, (d) 2010 and (e) 2016

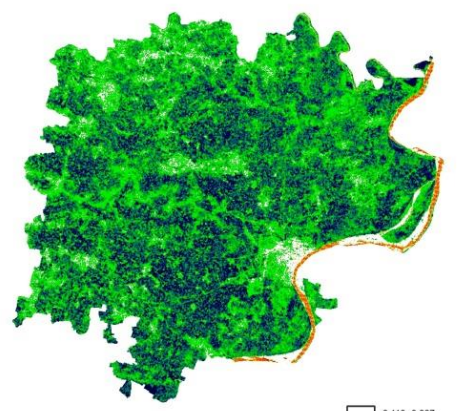

(a)

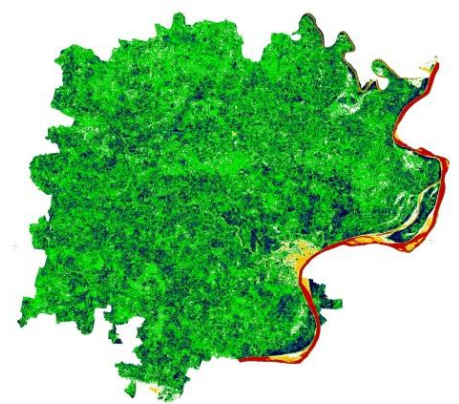

(b)

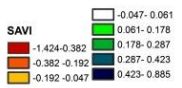

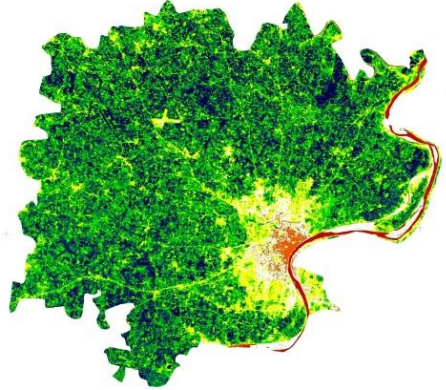

(c)

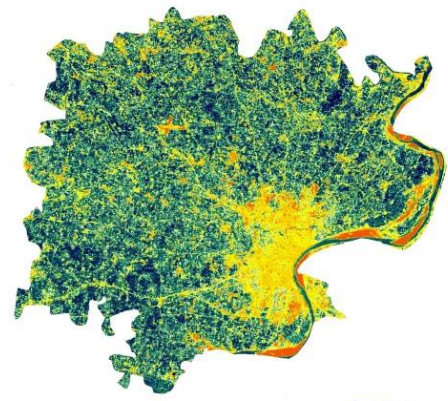

(d)

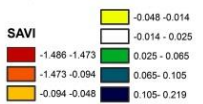

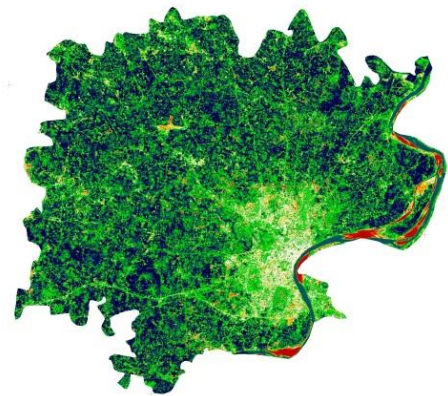

(e)

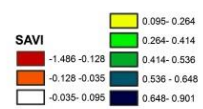

\section{CONCLUSION}

This paper presented the importance of using remotely sensed data as a means for the mapping and the detection of changes of land use land cover (LULC) in the Varanasi district. The results reveal clearly the significance of the use of multi-temporal Landsat data which offers an accurate and economical way of mapping and conducting analysis on the changes in LULC during the study period 1980-2016. The study has identified several patterns and trends of the changes in LULC in the area. The resulting products of the exploratory analyses and classification were used to assess spatial patterns of LULC mapping of the area. Supervised classification gave the results through all the stated classes and proved to be a more resourceful method for the detection of a change. The exploratory study of data through the use of NDVI's provided valuable analysis views and analytical masks for guiding classification measures.

It is apparent that urban expansion is maximum than all the other land classifications. In short, the results have shown that there is a significant increase in urban expansion leading to a significant drop in agricultural land use and vegetation during the study period. It is thought that the main explanation for therapid increase in urban area is population growth, migration from rural areas to the Varanasi city and more general economic development. The combined 
Singh S., Rai P.K..: Application of Earth observation data for estimation of changes in land trajectories in Varanasi District, India

findings will provide policymakers with scientific evidence of land use change and will identify the problems and/or opportunities for the study area. Future work with more multiseasonal satellite images and ground truth data may help to map the land cover changes with maximum level of accuracy.

\section{ACKNWLEDGEMENT}

The author's expresses their deep sense of gratefulness to USGS for providing Landsat data free of cost.

\section{REFERENCES}

Alrababah, M. A., \&Alhamad, M. N. (2006). Land use/cover classification of arid and semi-arid Mediterranean landscapes using Landsat ETM. International Journal of Remote Sensing, 27, 2703.

Asrar, G., M. Fuchs, E. T. Kanemasu, and J. H. Hatfield (1984), Estimating absorbed photosynthetic radiation and leaf area index from spectral reflectance in wheat, Agron J., 76, $300-306$.

Campbell, J. B. (1987). Introduction to Remote Sensing. The Guilford Press, New York, USA, $551 \mathrm{pp}$.

Chavula, G., Brezonik, P. \& Bauer, M. (2011). "Land Use and Land Cover Change (LULC) in the Lake Malawi Drainage Basin, 1982-2005", International Journal of Geosciences, vol. 2, no. 2, pp. 172-178.

Coppin, P., Jonckheere, I., Nackaerts, K., Muys, B. \&Lambin, E. (2004). Review article digital change detection methods in ecosystem monitoring: a review. International Journal of Remote Sensing 25:1565-1596.

Fan, F., Weng, Q. and Wang, Y., (2007). Land Use and Land Cover Change in Guangzhou, China, from 1998 to 2003, Based on Landsat TM /ETM+ Imagery, Sensors, 7, 1323-1342.

Fluor C.P., (2014). Absorptivity Module \& NDVI Measurement Instruction Manual, product PSI, spol. s r. o., Drásov 470, 66424 Drásov, Czech Republic

Im, J. \& Jensen, J.R., (2005). A change detection model based on neighborhood correlation image analysis and decision tree classification. Remote Sensing of Environment 99: 326-340.

Huete, A. R., (1988), A soil-adjusted vegetation index (SAVI), Remote Sens. Environ. 25:295-309.

Jovanović, D., Govedarica, M., Pržulj, Đ. (2007). The tracking use change area of Vojvodine Using shooting by passing LANDSAT ETM + and TM satellite images Vodoprivreda 0350-0519, 39, 229-230, 337-343.

Jovanović, D., Govedarica, M., Badnjarević, M., (2011). Presenting And Comparing the Object Based Image Analysis and Standard Image Analysis For Change Detection of Forest Areas, Using Low-Resolution Satellite Imagery. SGEM, 2, 11, 329-336.

Lillesand, T.M., Kiefer, R.W. and Chipman, J.W. (2008). Remote Sensing and Image Interpretation. 6th Edition, John Wiley \& Sons, Hoboken.

Lunetta R., (2004). Land-cover change detection using multi-temporal modis NDVI data, Remote Sensing of Environment, 105, 2006, 142-154. 
Liu J.G. \& Mason, P.J, (2009). Essential Image Processing and GIS for Remote Sensing. John Wiley \& Sons, Inc.

Junfeng, L., Zhibao, D., Guangyin, H., Changzhen, Y., Zhenhai, W., Xiang, S., (2011). Land use and land cover change and its driving forces in the source region of the Yangtze River during 1990-2005, International Symposium on Water Resource and Environmental Protection, IEEE, Xi'an, China.

Manandhar, R., Odeh, I. O. A., Ancev, T., (2009). Improving the Accuracy of Land Use and Land Cover Classification of Landsat Data using Post-classification Enhancement. Remote Sensing 1, 3, 330-344.

Matinfar H.R., Sarmadian F., Alavi Panah S.K., and Heck R.J., (2007). Comparisons of Object-Oriented and Pixel-Based Classification of Land Use/Land Cover Types Based on Lansadsat7, Etm+ Spectral Bands (Case Study: Arid Region of Iran)", American-Eurasian J. Agric. \& Environ. Sci., vol 2 (4), p.p. 448-456, 2007. ISSN 1818-6769, 2007

Mishra, V.N., Rai, P.K., Mohan, K. (2014). Prediction of land use changes based on land change modeler (LCM) using remote sensing: a case study of Muzaffarpur (Bihar), India. Journal of the Geographical Institute Jovan Cvijic SASA, 64: 111-127.

Mishra, V.N., and Rai, P.K. (2016). A remote sensing aided multi-layer perceptron-Markov chain analysis for land use and land cover change prediction in Patna district (Bihar), India. Arabian Journal of Geosciences, 9 (4):1-18. Doi: 10.1007/s12517-015-2138-3.

Mishra, V.N., Rai, P.K., Kumar, P. and Prashad, R., (2016). Evaluation of Land Use/Land Covers Classification Accuracy Using Multi-Temporal Remote Sensing Images, Forum Geographic (Romania), 15 (1), 45-53.

Macleod, R.D., \& Congalon, R.G., (1998). A quantitative comparison of change detection algorithms for monitoring eelgrass from remotely sensed data. Photogrammetric Engineering \& Remote Sensing 64:207-216.

McNairn, H., Protz, R., (1993). Mapping corn residue cover on agricultural fields in Oxford County, Ontario, using Thematic Mapper. Canadian Journal of Remote Sensing 19, 2, 152-159.

Pielke Sr., R. A., Marland, G., Betts, R. A., Chase, T. N., Eastman, J. L., Niles, J. O., Niyogi, Devdutta S., and Running, S. W., (2002). "The influence of land-use change and landscape dynamics on the climate system: relevance to climatechange policy beyond the radiative effect of greenhouse gases." Philosophical Transactions of the Royal Society A: Mathematical, Physical and Engineering Sciences, 360 (1797):1705-1719. doi:10.1098/rsta.2002.1027.

Prajapati, A., (2016). Land and Forest Management by Land Use/Land Cover Analysis \& Change Detection Technique Using Remote Sensing \& GIS, Journal of Landscape Ecology, Vol. 9 (3), 63-77. DOI: https://doi.org/10.1515/jlecol-2016-0005.

Qi, J., Moran, M. S., Huete, A. R., Jackson, R. D., Chehbouni, A., (1991). View atmosphere soil effect on vegetation indices derived from SPOT images. Proceedings of the 5th International Symposium Physical Measurements and Signatures in Remote Sensing, Courchevel, France 2, 785-790.

Rai, P.K., Sweta and Mishra, A. Onagh, M., (2011). Multi Seasonal IRS-IC LISS III data for Change Detection Analysis and Accuracy Assessment: A Case Study, Journal of GIS Trend, 2(2):13-19.

Rai, P.K., Singh, S. and Mohan, K., (2015). Land Use Change Detection Using Multi-Temporal Satellite Data: A Case Study of Haridwar District, Uttrakhand, Journal of 
Singh S., Rai P.K..: Application of Earth observation data for estimation of changes in land trajectories in Varanasi District, India

Scientific Research, (Banaras Hindu University), 59 (1 \& 2), 1-16.

Rozenstein, O. and Karnieli, A., (2011). Comparison of methods for land-use classification incorporating remote sensing and GIS inputs, Applied Geography, 31, pp. 533-544.

Singh, A., (1989). Digital Change Detection Techniques Using Remotely Sensed Data, International Journal of Remote Sensing 10, 6, 989-1003.

Van Lynden, G. W. J., and Mantel, S., (2001). "The role of GIS and remote sensing in land degradation assessment and conservation mapping: some user experiences and expectations." International Journal of Applied Earth Observation and Geoinformation, 3 (1):61-68. doi:10.1016/S0303-2434(01)85022-4.

Vishwakarma, C.S., Thakur, S., Rai, P.K., Kamal, V. and Mukharjee, S., (2016). Changing Land Trajectories: A Case Study from India Using Remote Sensing, European Journal of Geography. Vol. 7 (2), 63-73.

Williams, D. L., Goward, S., \&Arvidson, T., (2006). Landsat: yesterday, today, and tomorrow. Photogrammetric Engineering \& Remote Sensing, 72(10), 1171-1178.

Zaki R., Zaki A. and Ahmed S., (2011). "Land Use and Land Cover Changes in Arid Region: The Case New Urbanized Zone, Northeast Cairo, Egypt," Journal of Geographic Information System, Vol. 3 No. 3, pp. 173-194. doi: 10.4236/jgis.2011.33015. 